\title{
A comprehensive analysis of the animal carcinogenicity data for glyphosate from chronic exposure rodent carcinogenicity studies
}

\author{
Christopher J. Portier ${ }^{1,2,3}$ (D)
}

\begin{abstract}
Since the introduction of glyphosate-tolerant genetically-modified plants, the global use of glyphosate has increased dramatically making it the most widely used pesticide on the planet. There is considerable controversy concerning the carcinogenicity of glyphosate with scientists and regulatory authorities involved in the review of glyphosate having markedly different opinions. One key aspect of these opinions is the degree to which glyphosate causes cancer in laboratory animals after lifetime exposure. In this review, twenty-one chronic exposure animal carcinogenicity studies of glyphosate are identified from regulatory documents and reviews; 13 studies are of sufficient quality and detail to be reanalyzed in this review using trend tests, historical control tests and pooled analyses. The analyses identify 37 significant tumor findings in these studies and demonstrate consistency across studies in the same sex/species/strain for many of these tumors. Considering analyses of the individual studies, the consistency of the data across studies, the pooled analyses, the historical control data, non-neoplastic lesions, mechanistic evidence and the associated scientific literature, the tumor increases seen in this review are categorized as to the strength of the evidence that glyphosate causes these cancers. The strongest evidence shows that glyphosate causes hemangiosarcomas, kidney tumors and malignant lymphomas in male CD-1 mice, hemangiomas and malignant lymphomas in female CD-1 mice, hemangiomas in female Swiss albino mice, kidney adenomas, liver adenomas, skin keratoacanthomas and skin basal cell tumors in male Sprague-Dawley rats, adrenal cortical carcinomas in female SpragueDawley rats and hepatocellular adenomas and skin keratocanthomas in male Wistar rats.
\end{abstract}

Keywords: Glyphosate, Cancer, Animal carcinogenicity studies, Trend test, Historical controls

\section{Background}

Glyphosate acid (CAS \# 1071-81-6) is a colorless, odorless, crystalline solid. Glyphosate is the term used to describe the salt that is formulated by combining the deprotonated glyphosate acid and a cation (isopropylamine, ammonium, or sodium). Glyphosate was first synthesized in 1950 as a pharmaceutical compound but no pharmaceutical applications were identified. Glyphosate was reformulated in 1970 and tested for its herbicidal activity and was patented for use by Monsanto. The patent has since expired and

Correspondence: cportier@mac.com

${ }^{1}$ Rollins School of Public Health, Emory University, Atlanta, GA, USA

${ }^{2}$ Department of Toxicogenomics, Maastricht University, Maastricht, Netherlands

Full list of author information is available at the end of the article now glyphosate is produced worldwide by numerous manufacturers [1]. According to the International Agency for Research on Cancer [2], glyphosate is registered in over 130 countries as of 2010. Since the introduction of genetically engineered glyphosate-tolerant crops in 1996, the global use of glyphosate has increased 15 -fold making it the most widely used pesticide worldwide [3].

Most countries require a two-year rodent carcinogenicity study (cancer bioassay) be completed and the results reported to the proper authority in order to register a pesticide for use. There have been multiple cancer bioassays conducted to determine if glyphosate is potentially carcinogenic in humans. These have been reviewed by numerous regulatory agencies including the European Food Safety Authority (EFSA) [4], the European Chemicals 
Agency (EChA) [5], and the US Environmental Protection Agency (EPA) [6]. All of these agencies have concluded that the animal carcinogenicity data do not support a link between glyphosate and cancer. The carcinogenicity of glyphosate was also reviewed by the International Agency for Research on Cancer (IARC) [2] who found that the animal carcinogenicity data was sufficient to establish a causal link between exposure to glyphosate and cancer incidence in animals. The data have also been reviewed by the Joint Meeting of Pesticide Residues (JMPR) [7] concluding "that glyphosate is not carcinogenic in rats but could not exclude the possibility that it is carcinogenic in mice at very high doses."

There is considerable controversy over the interpretation of these cancer bioassays. Numerous reasons have been put forth to explain the differences between IARC and the regulatory agencies on the carcinogenicity of glyphosate in rodents. These differences will be discussed at the end of this report.

This report considers the adequacy of the studies for addressing the carcinogenicity of glyphosate and, where data is available, reanalyzes these data to identify significant increases in tumors in these data sets and compares the results across studies.

\section{Main text}

\section{Materials and methods}

\section{Animal carcinogenicity data}

The animal carcinogenicity data derives from multiple sources including the published literature, the EPA review [6], the Addendum to the EFSA review prepared by the German Institute for Risk Analysis [8], the JMPR review [7], Additional file 1 from a review of the carcinogenicity of glyphosate by a panel of scientists on behalf of industry [9], and the full laboratory reports (with redactions) for some of these studies following a recent court decision [10] (usually these full laboratory reports are not available to the public). In some cases, only limited data is reported for a given study making comparisons to other studies difficult. Only data from the core lifetime studies are included in the evaluation; data from interim sacrifices are not included.

In total, there are 13 chronic exposure animal toxicology and carcinogenicity studies of glyphosate in rats and 8 in mice (Tables 1 and 2). The full descriptions of most studies are available in either the published document in the literature, the regulatory reports, or, where available, the full laboratory reports. Table 1 lists the 13 chronic exposure toxicity and carcinogenicity studies considered acceptable for this evaluation and provides a brief description of the species, strain, exposure levels, group sizes, chemical purity and comments on survival and weight changes seen in the study. Twelve of these studies were conducted under the appropriate regulatory guidelines at the time they were conducted. A more complete description for each of these studies including the laboratory conducting the study, the substrain of the animal used (if given), a description of pathology protocols used, a list of tissues evaluated and a complete list of all tumors analyzed in this reanalysis is provided in the Additional file 1. Table 2 identifies 8 chronic exposure toxicity and carcinogenicity studies that are not included in this evaluation and the reasons for their exclusion such as falsified data, lack of tumor data, or chemical purity.

For 12 of these studies, the full study report is available. For study E (Takahashi [15]), a full study report is not available. JMPR [7] provided the only review of this study and only reported on kidney tumors in males and malignant lymphomas in females. This study is included in this review for only kidney tumors in males and malignant lymphomas in females.

Two additional chronic exposure studies of glyphosate formulations are included in this review as additional support for the carcinogenicity of glyphosate. These studies are not reanalyzed for this evaluation; the evaluations of the original authors are described in the Results section.

George et al. [35] exposed groups of 20 male Swiss Albino mice to a glyphosate formulation (Roundup Original, $360 \mathrm{~g} / \mathrm{L}$ glyphosate) at a dose of $25 \mathrm{mg} / \mathrm{kg}$ (glyphosate equivalent dose) topically three times per week, topically once followed one week later by 12-0tetradecanoylphorbol-13-acetate (TPA) three times per week, topically three times per week for three weeks followed one week later by TPA three times per week, or a single topical application of 7,12-dimethyl-ben$z$ [a]anthracene (DMBA) followed one week later by topical application of glyphosate three times per week for a total period of 32 weeks. Appropriate untreated, DMBAtreated, and TPA-treated controls were included.

Seralini, G. E., et al. [36] conducted a 24-month chronic toxicity study of Roundup (GT Plus, $450 \mathrm{~g}$ glyphosate/L, EU approval 2,020,448) in groups of 10 male and female Sprague-Dawley rats with drinkingwater exposures of $0,1.11 \cdot 10^{-8}, 0.09$, and $0.5 \%$ Roundup (males and females). This study noted an increase in mammary tumors. However, given the small sample sizes employed and the availability of more detailed studies, this study will be included in this review only as supporting information.

\section{Data analysis}

Individual tumor counts for the individual studies are reanalyzed using the exact form of the CochranArmitage (C-A) linear trend test in proportions [37]. Reanalyses are conducted on all primary tumors where there are at least 3 tumors in all of the animals in a sex/ 


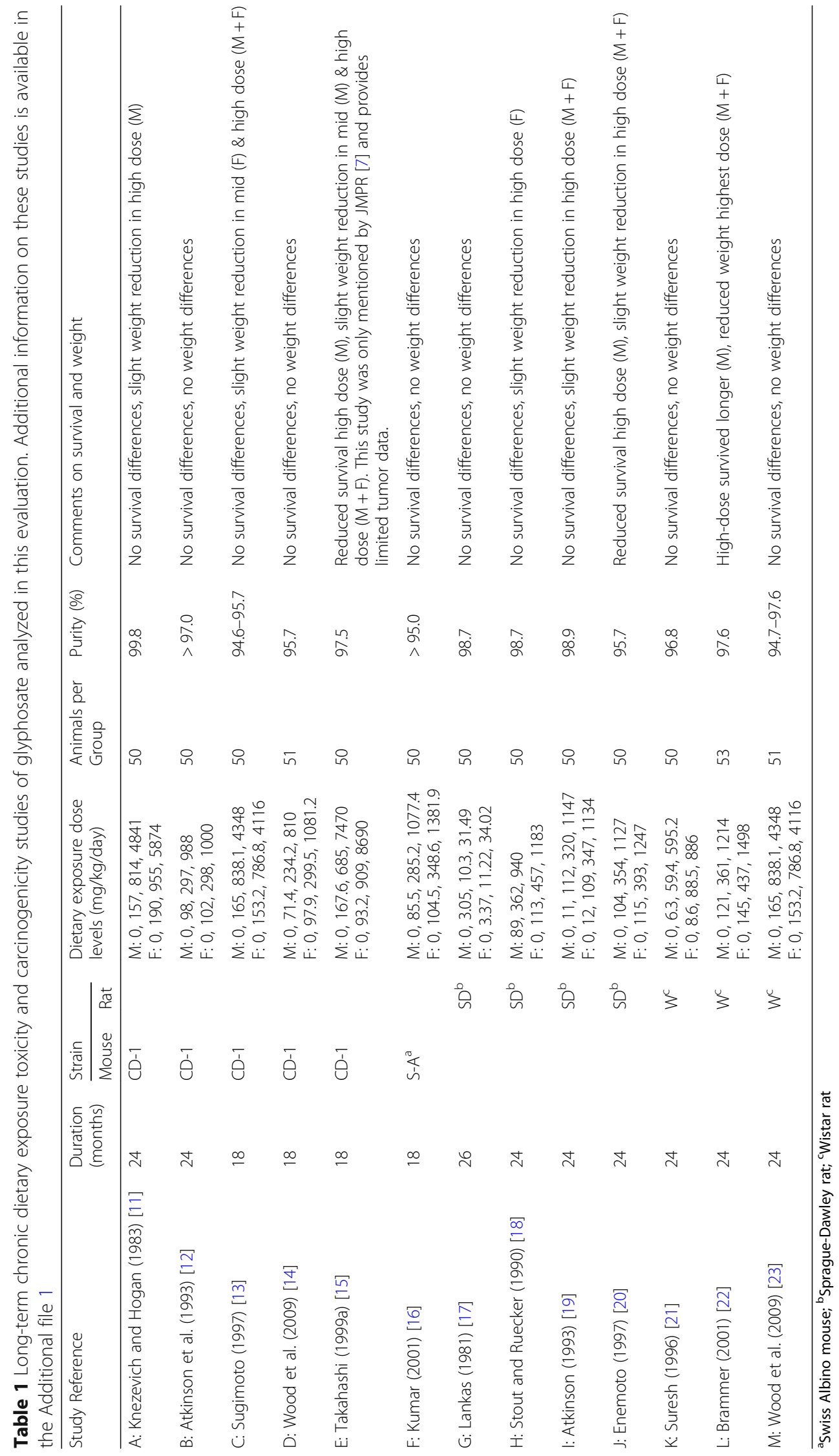


Table 2 Long-term chronic dietary exposure toxicity and carcinogenicity studies of glyphosate excluded from this evaluation

\begin{tabular}{|c|c|c|c|c|c|c|c|}
\hline \multirow[t]{2}{*}{ Study Reference } & \multirow{2}{*}{$\begin{array}{l}\text { Duration } \\
\text { (months) }\end{array}$} & \multicolumn{2}{|l|}{ Strain } & \multirow{2}{*}{$\begin{array}{l}\text { Dietary exposure } \\
\text { dose levels } \\
\text { (mg/kg/day) }\end{array}$} & \multirow{2}{*}{$\begin{array}{l}\text { Animals per } \\
\text { Group }\end{array}$} & \multirow[t]{2}{*}{ Purity (\%) } & \multirow[t]{2}{*}{ Reason for exclusion } \\
\hline & & Mouse & Rat & & & & \\
\hline $\begin{array}{l}\text { Reyna and Gordon } \\
\text { (1973) [24] }\end{array}$ & 18 & SWM $^{a}$ & & $\begin{array}{l}\text { M: } 0,17,50 \\
F: 0,17,50\end{array}$ & 50 & $N P^{b}$ & EPA [25] concluded this study was likely falsified \\
\hline $\begin{array}{l}\text { Pavkov and Turner } \\
\text { (1987) [26] }\end{array}$ & 24 & CD-1 & & $\begin{array}{l}\text { M: 0, 11.7, 118, } 991 \\
\text { F: 0, 11.7, 118, } 991\end{array}$ & 50 & 56.2 & $\begin{array}{l}\text { EPA [6] lists this study as completely negative for } \\
\text { tumors but provides no tumor data. No tumor data } \\
\text { is available for this study and the purity is low. }\end{array}$ \\
\hline $\begin{array}{l}\text { Reyna and Gordon } \\
\text { (1974) [27] }\end{array}$ & 24 & & $S D^{c}$ & Not available & 70 & 13.8 & EPA [25] concluded this study was likely falsified \\
\hline $\begin{array}{l}\text { Burnett et al. } \\
\text { (1979) [28] }\end{array}$ & 24 & & $\mathrm{SD}^{c}$ & $\begin{array}{l}\text { M: 0, 3.10.30 } \\
\text { F: 0, 3,10,30 }\end{array}$ & 90 & $N P^{b}$ & $\begin{array}{l}\text { EPA initially reported this as a glyphosate study [29] } \\
\text { but later removed it because it is a study of a } \\
\text { contaminant of glyphosate [6]. }\end{array}$ \\
\hline $\begin{array}{l}\text { Pavkov and } \\
\text { Wyand (1987) [30] }\end{array}$ & 24 & & $\mathrm{SD}^{c}$ & $\begin{array}{l}\text { M: } 0,4.2,21.2,41.8 \\
F: 0,5.4,27,55.7\end{array}$ & $80-90$ & 56.2 & $\begin{array}{l}\text { EPA [6] lists this study as completely negative for } \\
\text { tumors but provides very limited tumor data [31]. } \\
\text { No tumor data is available for this study and the } \\
\text { purity is low. }\end{array}$ \\
\hline Excel (1997) [32] & 24 & & $S D^{c}$ & $\begin{array}{l}\text { M: } 0,150,780,1290 \\
\text { F: } 0,210,1060,1740\end{array}$ & 51 & $N P^{b}$ & $\begin{array}{l}\text { No tumor data available, regulatory agencies had } \\
\text { concerns about the quality of the study and purity } \\
\text { of the material being studied }\end{array}$ \\
\hline $\begin{array}{l}\text { Takahashi } \\
\text { (1999b) [33] }\end{array}$ & 24 & & $F^{d}$ & $\begin{array}{l}\text { M: } 0,25,201,1750 \\
F: 0,29.7,239,2000\end{array}$ & 50 & $N P^{b}$ & $\begin{array}{l}\text { This study is only mentioned by JMPR [7] and showed } \\
\text { body weight changes at the highest exposure which } \\
\text { probably exceeded the MTD. No tumor data were } \\
\text { provided although JMPR concluded there is no } \\
\text { increased carcinogenicity. }\end{array}$ \\
\hline $\begin{array}{l}\text { Chruscielska } \\
\text { (2000) [34] }\end{array}$ & 24 & & $w^{e}$ & $\begin{array}{l}\text { M: } 1.9,5.9,17 \\
F: 0,2.2,6.5,19\end{array}$ & 85 & $\mathrm{GBH}^{\mathrm{f}}$ & $\begin{array}{l}\text { Uncertainty in the material used in the study and } \\
\text { poor reporting in the study. Note: this study is in } \\
\text { drinking water }\end{array}$ \\
\hline
\end{tabular}

${ }^{\mathrm{a}}$ Swiss white mouse; ${ }^{\mathrm{b}}$ Purity not provided; ${ }^{\mathrm{C}}$ Sprague-Dawley rat; ${ }^{\mathrm{d}}$ Fischer F344 rats; $^{\mathrm{e}}$ Wistar rats; ${ }^{\mathrm{f}}$ glyphosate-based herbicide (13.8\% solution, probably Perzocyd according to Greim et al. [9])

species/strain combination (regardless of dosing). In addition, any tumor where a positive finding $(p \leq 0.05$, one-sided C-A trend test) is seen in at least one study is also evaluated, regardless of number of animals with the tumor, in all studies of the same sex/species/strain. When adenomas and carcinomas are seen in the same tissue, a combined analysis of adenomas and carcinomas is also conducted. The minimum of three tumors is used since the exact version of the C-A test cannot detect tumors in studies of this size with less than at least 3 tumors. Additional file 2: Tables S1-S13 provide the tumor count data for all tumors with a significant trend test $(p \leq 0.05)$ in at least one study of the same sex/species/strain along with the doses used $(\mathrm{mg} / \mathrm{kg} /$ day) and the number of animals examined microscopically in each group. Pairwise comparisons between individual exposed groups and control are conducted using Fisher's exact test [37] and are provided for comparison with other reviews.

The C-A trend test belongs to the general class of logistic regression models [37]. To evaluate the consistency of a tumor finding across multiple studies using the same sexspecies-strain combinations, logistic regression with individual background responses and dose trends are fit to the pooled data using maximum likelihood estimation. In mathematical terms, the regression model being used is:

$$
p=\frac{e^{\alpha_{i}+\beta \cdot d o s e}}{1+e^{\alpha_{i}+\beta \cdot d o s e}}
$$

where $p$ is the probability of having a tumor, $\alpha_{i}$ is a parameter associated with the background tumor response (dose $=0$ ) for study $i$ and $\beta$ is a parameter associated with a change in the tumor response per unit dose (slope). A common positive trend is seen in the pooled analysis when the null hypothesis that the slope is 0 $\left(\mathrm{H}_{0}: \beta=0\right)$ is rejected (statistical $p$-value $\leq 0.05$ using a likelihood-ratio test) in favor of the alternative that the slope is greater than $0\left(\mathrm{H}_{\mathrm{A}}: \beta>0\right)$. The heterogeneity of slopes (all studies have different slopes vs all studies have a common slope) is tested using the model:

$$
p=\frac{e^{\alpha_{i}+\beta_{i} \cdot \text { dose }}}{1+e^{\alpha_{i}+\beta_{i} \cdot \operatorname{dos} e}}
$$

where $p$ and $\alpha_{i}$ are as in equation (1) and $\beta_{i}$ is a parameter associated with the slope for study $i$. Heterogeniety is seen in the pooled analysis when the null hypothesis that the slopes are equal $\left(\mathrm{H}_{0}: \beta_{1}=\beta_{2}=\beta_{3}=\ldots\right)$ is rejected (statistical $p$-value $\leq 0.05$ using a likelihood-ratio test) in favor of the alternative that at least one of the slopes is different.

For CD-1 mice, there are studies of 18 months (3) and 24 months (2) so analyses are conducted separately for 
18 month studies and 24 month studies and then a combined analysis is performed. In SD rats, one study had 26 months of exposure and the remaining 3 had 24 months of exposure so similar grouped analyses are conducted. Only the combined analysis over all study durations is provided in Tables 3, 4 and 5; the subanalyses by study duration are discussed in the text.

The same methods of analysis are used to evaluate the incidence of non-cancerous toxicity in tissues where positive cancer findings are seen. These findings are discussed in the text but not shown in the tables.

In some cases, tumors that rarely $(<1 \%$ in untreated animals) appear in laboratory animals can be increased but do not show statistical significance. Most guidelines call for the use of historical control data to evaluate these cases to assess the significance of the findings [38-40]. For these evaluations, the test proposed by Tarone [41] is used with an appropriate historical control group as discussed in the text.

All analyses were done using MATLAB, version R2017b.

\section{Conclusions}

\section{Results}

Thirteen chronic exposure animal carcinogenicity studies are reviewed and reanalyzed for this evaluation. The summary of all tumor findings with a Cochran-Armitage
(C-A) trend test (one-sided) of $p \leq 0.05$ in at least one study (by sex/species/strain) from the reanalysis of these studies are provided in Tables 3, 4 and 5 (columns under the heading "Individual study p-values for trend"). In addition, the $\mathrm{p}$-values for trend (under the heading "Common Trend") and heterogeneity (under the heading "Heterogeneity Test") from the analysis of the pooled data are also provided in Tables 3, 4 and 5. The individual tumor counts for each individual study are shown in Additional file 2: Tables S1-S13. In addition, a few tumors where there is a significant $(p \leq 0.05)$ pairwise comparison by Fishers exact test in at least one study but no significant trend tests are also summarized in Tables 3, 4 and 5; this is for comparison with regulatory reviews that generally used only pairwise comparisons.

The purpose of this analysis is to understand the tumorogenicity of glyphosate across all studies and not one study at a time. Thus, rather than presenting the results of each study separately, this review focuses on the tumors that are seen as positive in any one study and compares the findings across all studies of the same tumor in the same sex/species/strain combination.

\section{Reanalysis of the data from CD-1 Mice}

Table 3 summarizes the significant results seen from five studies conducted in CD-1 mice [11-15]. For a complete

Table $3 P$-values for the Cochran-Armitage trend test and pooled logistic regression analysis for tumors with at least one significant trend test $(p \leq 0.05)$ or Fisher's exact test $(p \leq 0.05)$ in male and female CD-1 mice

\begin{tabular}{|c|c|c|c|c|c|c|c|}
\hline \multirow{2}{*}{$\begin{array}{l}\text { Tumor } \\
\text { Males }\end{array}$} & \multicolumn{5}{|c|}{ Individual study $p$-values for trend ${ }^{a}$} & \multirow[t]{2}{*}{ Common Trend } & \multirow[t]{2}{*}{ Heterogeneity Test } \\
\hline & A & B & C & $\mathrm{D}$ & $\mathrm{E}$ & & \\
\hline Kidney Adenomas & $0.442(0.138)^{d}$ & 0.938 & $0.062(\mathbf{0 . 0 0 9})^{d}$ & $--^{b}$ & 0.019 & 0.006 & 0.268 \\
\hline Kidney Carcinomas & $0.063(<0.001)^{d}$ & 0.938 & $--^{b}$ & $--^{b}$ & 0.250 & 0.031 & 0.546 \\
\hline Kidney Adenomas and Carcinomas & $0.065(\mathbf{0 . 0 0 8})^{d}$ & 0.981 & $0.062(\mathbf{0 . 0 0 9})^{d}$ & $--^{b}$ & 0.005 & $<0.001$ & 0.106 \\
\hline Malignant Lymphomas & 0.754 & 0.087 & 0.016 & 0.007 & $N D^{c}$ & 0.093 & 0.007 \\
\hline Hemangiosarcomas & 0.505 & 0.004 & $0.062(\mathbf{0 . 0 0 5})^{d}$ & $---b$ & $N D^{c}$ & 0.033 & 0.007 \\
\hline Alveolar-Bronchiolar Adenomas & 0.294 & 0.231 & 0.513 & 0.924 & $N D^{c}$ & 0.384 & 0.409 \\
\hline Alveolar-Bronchiolar Carcinomas & 0.918 & 0.456 & 0.148 & 0.028 & $N D^{c}$ & 0.407 & 0.083 \\
\hline Alveolar-Bronchiolar Adenomas and Carcinomas & 0.576 & 0.231 & 0.294 & 0.336 & $N D^{c}$ & 0.346 & 0.826 \\
\hline Females & A & B & C & D & $\mathrm{E}$ & & \\
\hline Hemangiomas & 0.631 & $--^{b}$ & 0.002 & 0.438 & $N D^{c}$ & 0.031 & 0.155 \\
\hline Harderian Gland Adenomas & 0.877 & $N^{c}$ & 0.040 & 0.155 & $\mathrm{ND}^{c}$ & 0.155 & 0.052 \\
\hline Harderian Gland Carcinomas & $--^{b}$ & $N D^{c}$ & $--^{b}$ & 1.000 & $N D^{c}$ & 0.500 & 1.00 \\
\hline Harderian Gland Adenomas and Carcinomas & 0.877 & $N D^{c}$ & 0.040 & 0.372 & $N D^{c}$ & 0.184 & 0.110 \\
\hline Alveolar-Bronchiolar Adenomas & 0.999 & 0.144 & 0.800 & 0.656 & $N D^{c}$ & 0.996 & 0.211 \\
\hline Alveolar-Bronchiolar Carcinomas & 0.183 & 0.110 & 0.623 & 0.601 & $\mathrm{ND}^{c}$ & 0.268 & 0.544 \\
\hline Alveolar-Bronchiolar Adenomas and Carcinomas & 0.985 & 0.048 & 0.842 & 0.688 & $N D^{c}$ & 0.982 & 0.241 \\
\hline Malignant Lymphomas & $0.070^{\mathrm{e}}$ & 0.484 & 0.294 & 0.353 & 0.050 & 0.012 & 0.995 \\
\hline
\end{tabular}

a - Study A is Knezevich and Hogan [11] (Additional file 2: Table S1), Study B is Atkinson et al. [12] (Additional file 2: Table S2), Study C is Sugimoto [13]

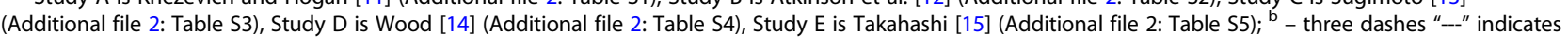
all tumor counts are zero; ${ }^{C}-$ ND indicates there is no data available for this tumor in this study; ${ }^{d}$ - using historical control data (see text for details) and Tarone's test; ${ }^{\mathrm{e}}$ - Spleen composite lymphosarcomas (malignant lymphomas) are also significantly increased in female mice in this study (see Additional file 2: Table S1) 
Table $4 P$-values for the Cochran-Armitage trend test and pooled logistic regression analysis for tumors with at least one significant trend test or Fisher's exact test $(p \leq 0.05)$ in male and female Sprague-Dawley rats

\begin{tabular}{|c|c|c|c|c|c|c|}
\hline \multirow{2}{*}{$\begin{array}{l}\text { Tumor } \\
\text { Males }\end{array}$} & \multicolumn{4}{|c|}{ Individual study $p$-values for trend ${ }^{a}$} & \multirow[t]{2}{*}{ Common Trend } & \multirow[t]{2}{*}{ Heterogeneity Tes } \\
\hline & G & $\mathrm{H}$ & I & J & & \\
\hline Testicular Interstitial Cell Tumors & 0.009 & 0.296 & 0.580 & 0.594 & 0.461 & 0.105 \\
\hline Pancreas Islet Cell Adenomas & 0.512 & $0.147(\mathbf{0 . 0 0 7})^{c}$ & 0.974 & 0.859 & 0.849 & 0.143 \\
\hline Pancreas Islet Cell Carcinomas & 0.251 & 1.000 & - & 0.500 & 0.731 & 0.166 \\
\hline Pancreas Islet Cell Adenomas or Carcinomas & 0.316 & 0.206 & 0.974 & 0.844 & 0.875 & 0.185 \\
\hline Thyroid C-cell Adenomas & 0.743 & 0.089 & 0.278 & 0.631 & 0.210 & 0.532 \\
\hline Thyroid C-cell Carcinomas & 0.505 & 0.442 & 0.495 & 0.565 & 0.322 & 0.898 \\
\hline Thyroid C-cell Adenomas and Carcinomas & 0.748 & 0.097 & 0.197 & 0.642 & 0.175 & 0.526 \\
\hline Thyroid Follicular-cell Adenomas & 0.122 & 0.408 & 0.067 & 0.966 & 0.464 & 0.055 \\
\hline Thyroid Follicular-cell Carcinomas & $--^{b}$ & 0.255 & 0.443 & 1.000 & 0.448 & 0.137 \\
\hline Thyroid Follicular-cell Adenoma and Carcinoma & 0.122 & 0.232 & 0.099 & 0.986 & 0.446 & 0.031 \\
\hline Hepatocellular Adenomas & 0.471 & 0.015 & 0.325 & 0.500 & 0.029 & 0.664 \\
\hline Hepatocellular Carcinomas & 0.062 & 0.637 & 0.760 & 0.642 & 0.803 & 0.269 \\
\hline Hepatocellular Adenomas and Carcinomas & 0.173 & 0.050 & 0.480 & 0.690 & 0.144 & 0.428 \\
\hline Kidney Adenomas & 0.938 & 0.813 & 1.000 & 0.004 & 0.039 & 0.002 \\
\hline Skin Keratoacanthomas & $--^{b}$ & 0.042 & 0.047 & 0.029 & $<0.001$ & 0.998 \\
\hline Skin Basal Cell Tumors & 0.251 & 0.249 & 1.000 & 0.004 & $<0.001$ & 0.009 \\
\hline Females & G & $\mathrm{H}$ & I & J & & \\
\hline Thyroid C-cell Adenomas & 0.679 & 0.049 & 0.207 & 0.912 & 0.287 & 0.150 \\
\hline Thyroid C-cell Carcinomas & $0.003(<0.001)^{c}$ & 0.500 & $--^{b}$ & $--^{b}$ & 0.385 & 0.041 \\
\hline Thyroid C-cell Adenomas and Carcinomas & $0.072(\mathbf{0 . 0 3 7})^{c}$ & 0.052 & 0.207 & 0.912 & 0.275 & 0.071 \\
\hline Adrenal Cortical Adenoma & 0.851 & 0.603 & $--^{b}$ & 0.626 & 0.713 & 0.750 \\
\hline Adrenal Cortical Carcinoma & 0.386 & 0.015 & 0.493 & $--^{b}$ & 0.031 & 0.199 \\
\hline Adrenal Cortical Adenoma and Carcinoma & 0.801 & 0.090 & 0.493 & 0.626 & 0.195 & 0.520 \\
\hline
\end{tabular}

a - Study G is Lankas [17] (Additional file 2: Table S7), Study H is Stout and Ruecker [18] (Additional file 2: Table S8), Study I is Atkinson et al. [12] (Additional file 2: Table S9) and Study J is Enemoto [20] (Additional file 2: Table S10); ${ }^{b}$ - three dashes "--." indicates all tumor counts are zero; ${ }^{\mathrm{c}}$ - using historical control data (see text for details) and Tarone's test

list of all the tumors evaluated, see the Additional file 1. For simplicity, these studies will be referred to as studies A-E as noted in Table 1. Studies A and B are 24-month studies and studies C, D and E are 18-month studies. There are a total of 12 statistically significant tumor findings $(p \leq 0.05)$ against the concurrent controls in these studies. In addition, there are 5 significant increases in tumors seen for rare tumors using historical controls.

Significant trends for kidney adenomas $(p=0.019)$ and adenomas and carcinomas combined $(p=0.005)$ are seen in male mice in study $\mathrm{E}$, marginal trends are seen in study A $(p=0.065)$ and study C (0.062) for combined adenomas and carcinomas with no increase in the remaining two studies. Kidney tumors are rare in CD-1 mice and it would be appropriate to compare the marginal responses against historical controls. Using historical control data for kidney tumors from the EPA archives [42] on study A results in no significant association with adenomas $(p=0.138)$ but significant increases in carcinomas $(p<0.001)$ and adenomas and carcinomas combined $(p=0.008)$ by Tarone's test. Using historical controls from 1990 to 1995 from the literature [43] results in a significant trend $(p=0.009)$ for kidney adenomas in Study C. The pooled analysis of the data shows a significant common trend for adenomas, carcinomas and the combined tumors with no indication of heterogeneity. Because of toxicity in the highest dose of study $\mathrm{E}$, a second pooled analysis is done dropping this dose and yields a significant increase for adenomas $(p=0.038)$ and carcinomas and adenomas combined $(p=0.011)$ and a marginal increase for carcinomas $(p=0.077)$ with no heterogeneity (not shown). Data on the incidence of kidney toxicity in these studies is also reanalyzed. Study A has a significant increase in chronic interstitial nephritis $(p=0.004)$ and a non-significant increase in thickening of the glomerular and/or tubular basal membranes $(p=$ 0.148 ) with a significant pairwise increase at the middose $(p=0.036)$. Study B has an increase in tubular dilatation $(p=0.026)$ but no change in tubular hypertrophy 
Table 5 -values for the Cochran-Armitage trend test and pooled logistic regression analysis for tumors with at least one significant trend test or Fisher's exact test $(p \leq 0.05)$ in male and female Wistar rats

\begin{tabular}{|c|c|c|c|c|c|}
\hline \multirow{2}{*}{$\begin{array}{l}\text { Tumor } \\
\text { Males }\end{array}$} & \multicolumn{3}{|c|}{ Individual study $p$-values for trend ${ }^{a}$} & \multirow[t]{2}{*}{ Common Trend } & \multirow[t]{2}{*}{ Homogeneity Tes } \\
\hline & K & $\mathrm{L}$ & M & & \\
\hline Hepatocellular Adenomas & 0.391 & 0.008 & 0.418 & 0.048 & 0.156 \\
\hline Hepatocellular Carcinomas & 0.418 & $--^{b}$ & 1.000 & 0.492 & 0.242 \\
\hline Hepatocellular Adenomas and Carcinomas & 0.286 & 0.008 & 0.610 & 0.029 & 0.194 \\
\hline Pituitary Adenomas & 0.376 & 0.277 & 0.045 & 0.057 & 0.664 \\
\hline Pituitary Carcinomas & 0.692 & $--{ }^{b}$ & 1.000 & 0.771 & 0.956 \\
\hline Pituitary Adenomas and Carcinomas & 0.454 & 0.277 & 0.059 & 0.073 & 0.700 \\
\hline Skin Keratoacanthomas & $---b$ & 0.387 & 0.030 & 0.032 & 0.823 \\
\hline Adrenal Pheochromocytomas & 0.048 & 0.721 & 0.306 & 0.273 & 0.210 \\
\hline Females & K & L & M & & \\
\hline Mammary Gland Adenomas & 0.539 & 0.941 & 0.062 & 0.448 & 0.015 \\
\hline Mammary Gland Adenocarcinomas & 1.000 & 0.271 & 0.042 & 0.071 & 0.008 \\
\hline Mammary Gland Adenomas and Adenocarcinomas & 0.729 & 0.590 & 0.007 & 0.113 & 0.064 \\
\hline Pituitary Adenomas & 0.967 & 0.261 & 0.014 & 0.105 & 0.023 \\
\hline Pituitary Carcinomas & 1.000 & - & 0.750 & 0.748 & 0.491 \\
\hline Pituitary Adenomas and Carcinomas & 0.976 & 0.261 & 0.017 & 0.129 & 0.019 \\
\hline
\end{tabular}

a - Study J is Suresh [21] (Additional file 2: Table S11), Study K is Brammer [22] (Additional file 2: Table S12), and Study L is Wood et al. [14] (Additional file 2: Table S13); ${ }^{\text {b }}$ - three dashes "---" indicates all tumor counts are zero

$(p=0.642)$ or focal tubular atrophy $(p=0.248)$. Study C has no change in tubular dilatation $(p=0.913)$ but does show an increase in tubular atrophy $(p=0.017)$ and tubular vacuolation $(p=0.015)$. Study D has no changes in vacuolation $(p=0.830)$, dilatation $(p=0.831)$, or chronic nephropathy $(p=0.494)$. Study E has an increase in kidney tubular dilation $(p<0.001)$, tubular epithelial cell hypertrophy $(p<0.001)$, basophilic tubules $(p=$ $0.009)$ and tubular degeneration and/or necrosis $(p=$ $0.008)$.

Malignant lymphomas are significant in studies $\mathrm{C}(p=$ $0.016)$ and $\mathrm{D}(p=0.007)$ and marginally significant in study B $(p=0.087)$ in male mice. Malignant lymphomas are not rare in these mice so no historical control analysis is conducted. The pooled analysis for a common trend is marginally significant $(p=0.093)$ and the studies are heterogeneous in slope because of the markedly different response in study A. The pooled analysis of the 18 month studies is highly significant $(p=0.005)$ but not significant for the 24 month studies $(p=0.686)$. Toxicity in tissues relating to the lymphatic system is reanalyzed. Study B shows a significant increase in thymus weight in the two highest exposure groups $(p<0.01$ and $p<0.05$, reported in [12]) in males and a non-significant ( $p$ not reported) increase in females. Studies $B$ and $C$ show a significant increase (trend test) in the number of males with enlarged mesenteric lymph nodes $(p=0.024$ and $p=0.002$ respectively). Study B shows enlarged spleens $(p=0.031)$ in males whereas $C$ did not. Study $C$ also has an increase in enlarged cervical lymph nodes $(p=0.046)$ and other lymph nodes $(p=0.047)$. Study A did not report macroscopic findings, study $\mathrm{D}$ has no enlarged lymphoreticular tissues and the data are not available from study E.

Hemangiosarcomas are statistically significant in study B $(p=0.004)$ and marginally significant in study C ( $p=$ $0.062)$ in male mice. Hemangiosarcomas are very rare in 18-month animals with no tumors appearing in 26 historical control data sets and moderately rare $(2.1 \%)$ in 24-month studies [43]. Using the 18-month historical control data [43] results in a significant finding for study $\mathrm{C}(p<0.001)$. The pooled analysis for a common trend is significant $(p=0.03)$ but the studies are heterogeneous in slope.

Although there is a single positive finding in the lung in male mice with a significant increase in carcinomas in study $\mathrm{D}(p=0.028)$, all of the other analyses in the lung are not statistically significant including the pooled analyses. There are no dose-related non-neoplastic findings in the lungs of these animals.

In female mice, hemangiomas are significantly increased in study C $(p=0.002)$ and the pooled analyses is also significant $(p=0.031)$ with no evidence of heterogeneity. Study $C$ has a $10 \%$ response at the highest dose whereas the other studies have much lower response resulting in the positive pooled association.

Harderian gland adenomas are significantly increased in study $C(p=0.04)$ but are not significant for studies A and $\mathrm{D}$ for adenomas, carcinomas and their combination. The pooled analyses fails to demonstrate a consistent 
increase. There are no non-neoplastic findings in the Harderian glands.

There is a significant increase in adenomas and carcinomas combined in the lung for female mice in study B $(p=0.048)$. None of the pooled analyses or any analyses in the remaining studies are significantly increased in the lung. There are no non-neoplastic findings in the lungs of these animals.

Finally, malignant lymphomas are significantly increased in study E $(p=0.050)$ and marginally increased in study A $(p=0.070)$ for females. The remaining studies show trends toward increasing risk with increasing exposure and when combined, the five mice studies show a significant increase in malignant lymphomas in female mice $(p=0.012)$ and no heterogeneity. The pooled analysis remains significant $(\mathrm{p}=0.050)$ if the high dose group from study $\mathrm{E}$ is removed due to high toxicity. There are no increases in enlargement of lymphoreticular tissues in female mice in studies $\mathrm{B}, \mathrm{C}$ and $\mathrm{D}$ and no data available for studies A and E.

\section{Reanalysis of the data from Swiss albino mice}

There is a single study in Swiss albino mice (study F). This study shows a significant increase in hemangiomas in female mice $(p=0.004)$ and marginal increases for malignant lymphomas in males $(p=0.064)$ and females $(p=0.070)$ and kidney adenomas in males $(p=0.090)$ (Additional file 2: Table S6). There are no kidney carcinomas in the males. There are no non-neoplastic changes in the kidney. Study F shows a significant increase in the incidence of thymus enlargement in males $(p=0.034)$ and a marginal increase in enlargement of mesenteric lymph nodes in females $(p=0.053)$ but not in males. For a complete list of all the tumors evaluated, see the Additional file 1.

\section{Reanalysis of the data from SD rats}

Table 4 summarizes the significant results seen from four studies conducted in SD rats [17-20]. For a complete list of all the tumors evaluated, see the Additional file 1 . Study G is a 26 -month study and studies $\mathrm{H}$, I and J are 24-month studies. There are a total of 11 statistically significant tumor findings $(p \leq 0.05)$ against the concurrent controls in these studies and three significant finding against historical controls.

Study G showed a significant increase in testes interstitial-cell tumors $(p=0.009)$ but no increases in any other study and the pooled analysis for a common trend is also non-significant. There are no nonneoplastic lesions seen in the testis in studies G, H and J. Study I saw a marginal increase $(p=0.092)$ in interstitial cell hyperplasia of the testis.

Pancreas islet-cell tumors, thyroid c-cell tumors and thyroid follicular-cell adenomas and carcinomas in males are presented in Table 4. None of these studies demonstrate a significant trend in any of these tumors nor do they show a significant trend in the pooled analyses. These tumors are included here for completeness because they have been mentioned in some of the regulatory reviews of these data due to increases in at least one dose group over controls using Fisher's exact test. Study G shows an increase in pancreatic islet cell adenomas in males at the low dose and study $\mathrm{H}$ shows increases in males at both the low dose and the high dose. Historical control data on pancreas islet-cell tumors in study $\mathrm{H}$ are provided in an EPA memo [44] and Tarone's historical control test yields a highly significant response for this study $(p=0.007)$ with all of the treated groups showing greater tumor response than any of the controls. There are no dose-related increases in islet cell non-neoplastic findings in any of the four studies in male Sprague-Dawley rats.

Study $\mathrm{H}$ saw an increase in males of thyroid C-cell adenomas at the mid and high doses and an increase in adenomas and carcinomas combined at all three doses tested. However, the control response in study $\mathrm{H}$ for these tumors is quite low with no tumors in 50 animals whereas the historical rate of tumors in this strain of rats is $11.3 \%$ in males [45]. Reanalyzing data on nonneoplastic toxicity, Study I has a significant increase in focal C-cell hyperplasia $(p=0.048)$ and no other studies have significant increases in C-cell hyperplasia.

Study I shows a marginally significant trend in males of thyroid follicular cell adenomas $(p=0.067)$ and adenomas and carcinomas combined $(p=0.099)$. No nonneoplastic endpoints show dose-related changes for thyroid follicular cells in any study.

Hepatocellular adenomas $(p=0.015)$ and adenomas and carcinomas combined $(p=0.050)$ are increased in males in study I but not in any of the other studies. The increases in adenomas remained significant $(p=0.029)$ in the pooled analysis since most studies showed a very slight increase in these tumors, but the pooled analysis for a common trend in adenomas and carcinomas is not significant $(p=0.144)$. After reanalysis of these studies for non-neoplastic toxicity, study $G$ shows a significant increase in basophilic foci $(\mathrm{p}=0.029)$, study $\mathrm{H}$ did not report on these and studies I and J show non-significant trends with the pooled analysis for a common trend not significant $(p=0.358)$. Study $\mathrm{G}$ has an increase in clearcell foci $(p=0.033)$, study I has a marginal increase in clear-cell foci $(p=0.057)$ and study $\mathrm{J}$ is non-significant with the pooled analysis showing a marginally significant trend $(p=0.073)$.

Kidney adenomas are increased in males $(p=0.004)$ in study J but not in any other study. The pooled analysis for a common trend is significant $(p=0.039)$ with significant heterogeneity because of the high response in 
study J and the generally low response in the remaining three studies. The only non-neoplastic pathology in the kidney is an increase in lymphocytic infiltration $(p=$ 0.037) in study G.

No skin keratoacanthomas are seen in males in study F, but these tumors are significantly increased in the other three studies $(p=0.042,0.047$ and 0.029$)$ and are highly significant in the pooled analysis for a common trend $(p<$ 0.001 ) with no apparent heterogeneity. After reanalysis of non-neoplastic toxicity, focal hyperkeratosis is increased in both sexes $(p \leq 0.001-\mathrm{M} ; p=0.015-\mathrm{F})$ in study J and shows a significant decrease in study I in males $(p=0.004)$.

Skin basal cell tumors in males are significantly increased in study J $(\mathrm{p}=0.004)$ and in the pooled analysis for a common trend $(p<0.001)$ but not in any of the other three studies. The pooled analysis demonstrates significant heterogeneity $(p=0.009)$, driven by the responses at lower doses in studies $\mathrm{G}$ and $\mathrm{H}$.

In females, thyroid $\mathrm{C}$-cell adenomas are significantly increased in study $\mathrm{H}(p=0.049)$, carcinomas are significantly increased in study G $(p=0.003)$ and adenomas and carcinomas combined are marginally significantly increased in studies $\mathrm{G}(p=0.072)$ and $\mathrm{H}(p=0.052)$. The authors of study $\mathrm{G}$ provided historical control data from 9 control groups for carcinomas and adenomas and carcinomas combined for these tumors; Tarone's test yielded $p<0.001$ for the carcinomas and $p=0.037$ for the combined tumors. None of the pooled analyses are statistically significant. There are no non-neoplastic changes in thyroid C-cells in females in these studies.

Adrenal cortical carcinomas are increased in females in study $\mathrm{H}(p=0.015)$ and adenomas and carcinomas are marginally increased $(p=0.090)$ in that same study. The pooled analysis for a common trend of the cortical carcinomas is significantly increased $(p=0.031)$ with little indication of heterogeneity, but the pooled analysis of the combined adenomas and carcinomas is not significantly increased. After reanalysis of non-neoplastic toxicity, focal cortical hypertrophy shows a dose-related significant increase in studies G $(p=0.048)$ and I $(p=$ 0.027), study $\mathrm{H}$ did not report hypertrophy independent of hyperplasia (the combined counts showed no increased dose-response), and study J did not report hypertrophy. There are no other dose-related increases in injury to adrenal cortical tissue in any of the studies.

\section{Reanalysis of the data from Wistar rats}

Table 5 summarizes the significant results seen from three studies conducted in Wistar rats [21-23]. For a complete list of all the tumors evaluated, see the Additional file 1. All three studies are 24-month studies. There are a total of 9 statistically significant tumor findings $(p \leq 0.05)$ against the concurrent controls in these studies.
Hepatocellular adenomas $(p=0.008)$ and combined adenomas and carcinomas $(p=0.008)$ in males are increased in study L but not in any other study (note, there are no carcinomas seen in this study so these analyses are identical). The pooled analyses for a common trend shows an increase for adenomas $(p=0.048)$, no increase in carcinomas (0.492) and an increase in combined adenomas and carcinomas $(p=0.029)$ with no indication of heterogeneity across the studies. Reanalysis of the non-neoplastic toxicity data show there is a significant decrease in basophilic-cell foci in study $\mathrm{K}(p=$ $0.023)$, no foci at all in study $\mathrm{L}$ and no trend in study $\mathrm{M}$. Clear-cell foci are not impacted by glyphosate in male Wistar rats.

Pituitary adenomas are increased in both males ( $p=$ $0.045)$ and females $(p=0.014)$ in study M but not in the remaining studies. Carcinomas show no increase in any study but the combined adenomas and carcinomas are marginally significant in males $(p=0.059)$ and significant in females $(p=0.017)$ in study M but not in the others. None of the pooled analyses for a common trend are statistically significant although the pooled trend in males is marginally significant for both adenomas $(p=$ $0.057)$ and combined adenomas and carcinomas ( $p=$ 0.073). There are no dose-dependent increases in any non-neoplastic lesion in male or female Wistar rats in any of the three studies.

Skin keratoacanthomas are significantly increased in males in study $\mathrm{M}(p=0.030)$ and in the pooled analysis for a common trend $(p=0.032)$ with no heterogeneity. There are no keratoacanthomas in study $\mathrm{K}$ and a slight increase with dose in study L. No non-neoplastic pathologies are significantly linked to dose in the skin.

Adrenal pheochromocytomas are increased in study $\mathrm{K}$ $(p=0.048)$ but not in the other studies or in the pooled analysis. There are no significant trends in nonneoplastic findings in any of the three studies.

Mammary gland adenomas $(p=0.062)$, adenocarcinomas $(p=0.042)$ and their combination $(p=0.007)$ are all increased in study $\mathrm{M}$, but not in the remaining studies. There is a marginal increase in adenocarcinomas in the pooled analysis for a common trend $(p=0.071)$ but not for the combined tumors $(p=0.110)$. The data suggests that all three endpoints demonstrated heterogeneity. Studies L and $\mathrm{M}$ also have fibroadenomas as well as adenomas and adenocarcinomas. Combining fibroadenomas, adenomas and adenocarcinomas results in no significant findings in any study or in the pooled analysis for this combination. Hyperplasia in mammary tissue is examined in all three studies with no significant findings in any study.

\section{Related findings from the peer-reviewed literature}

There are numerous studies in the literature that relate to the cancer findings shown in Tables 3, 4 and 5. Some 
of the studies are done using pure glyphosate, but many use a GBH and present the results in glyphosateequivalent doses. GBHs contain adjuvants, some of which are also likely to be highly toxic. In what follows, these related studies are discussed and care is taken to note whether the exposure is to glyphosate or a GBH. Caution should be used in interpreting the results using the GBHs since, in most cases, it is not clear if the resulting toxicity is due to the glyphosate in the GBH or the adjuvant(s).

Increases in kidney adenomas and carcinomas (combined) are seen in male CD-1 mice and increases in adenomas are seen in Swiss albino mice and SD rats in the reanalysis in this review. A number of short-term toxicity studies have demonstrated damage to the kidneys in laboratory animals from exposure to glyphosate or GBHs. Turkman et al. [46] saw significant $(p<0.05)$ increases in malondialdehyde (MDA) levels and decreases in glutathione (GSH) levels in male Wistar albino rats exposed to the GBH Knockdown 48SL. They also saw degeneration in the tubulur epithelial cells and expansion and vacuolar degeneration in glomerulus Bowman's capsule ( $p<0.05$ for both). Dedeke et al. [47] also saw significant changes in MDA, GSH and several other kidney biomarkers from exposure to the GBH Roundup in male albino rats. They also studied glyphosate alone in equal doses to the GBH and saw smaller, but still significant increases in MDA and GSH, but not in the other biomarkers. In addition, they found that the amount of glyphosate in kidney tissue was substantially higher from exposure to the GBH than from exposure to glyphosate alone. Tang et al. [48] saw proximal and distal tubular necrosis $(p<0.01)$, glomerular toxicity $(p<0.01)$ and a reduction in weight $(p<0.05)$ in the kidneys of male SD rats exposed to glyphosate. They used a histopathological score and saw significant changes $(p<0.01)$ even down to a dose of $5 \mathrm{mg} / \mathrm{kg}$ body weight. Hamdaoui et al. [49] saw numerous histological changes and changes in urine and plasma associated with renal disfunction in female Wistar rats exposed to the GBH Kalach 360 SL. Kidney damage included fragmented glomeruli, necrotic epithelial cells, and tubular dilatation, inflammation, proximal tubular necrosis and distal tubular necrosis. Tizhe et al. [50] also saw glomerular degeneration, mononuclear cell infiltration and tubular necrosis in male and female Wistar rats exposed to the GBH Bushfire. Cavusoglu et al. [51] saw similar changes in blood chemistry and kidney pathology in male albino mice exposed to the GBH Roundup Ultra-Max. Wang et al. [52] saw kidney damage to tubular cells in $\mathrm{Vk}^{*} \mathrm{MYC}$ mice exposed to glyphosate in water.

In humans, GBHs are suspected to be involved in chronic kidney disease of unknown etiology $(\mathrm{CKDu})$ in Sri Lanka, Mexico, Nicaragua, El Salvador and India
[53-55]. Finally, the English abstract of a Chinese article by Zhang et al. [56] describe significant increases $(p<$ 0.05 ) in abnormal hepatorenal function in workers occupationally exposed to glyphosate from 5 glyphosateproducing factories.

Dose-related increases in malignant lymphomas are seen in male and female CD-1 mice and marginal increases are seen in male and female Swiss albino mice in the reanalysis presented here. Wang et al. [52] exposed male and female $\mathrm{Vk}^{*} \mathrm{MYC}$ mice from the $\mathrm{C} 57 \mathrm{Bl} / 6$ genetic background to glyphosate (purity not provided) at an exposure of $1 \mathrm{~g} / \mathrm{L}$ in drinking water for 72 weeks (approximately 18 months) with an appropriate control. In addition, using the same mice, 7-day exposures were given at doses of $0,1,5,10$ and $30 \mathrm{~g} / \mathrm{L}$ of glyphosate ( $n=5$ per group). Glyphosate induced splenomegaly in both wild type (WT) and Vk*MYC mice. Both WT and $V k^{*} \mathrm{MYC}$ mice demonstrated a significant increase $(p<$ $0.05)$ in IgG levels when compared to controls. $\mathrm{Vk}^{*} \mathrm{MYC}$ treated mice had a clear M-spike (an indicator of multiple myeloma - MM), WT mice had a weaker M-spike and no $\mathrm{M}$-spike was detected in untreated animals regardless of genetics. In addition, there were multiple hematological abnormalities in treated versus untreated mice that were consistent with MM. Activation-induced cytidine deaminase (AID, a marker of monoclonal gammopathy of undetermined significance induction, a precursor of MM) was upregulated in both bone marrow and spleen of both $\mathrm{Vk}^{*} \mathrm{MYC}$ and WT mice in the 72 week study. The same upregulation in the spleen and bone marrow were seen in the 7-day exposure animals in a dose-dependent fashion. A smaller dose-dependent increase was seen in lymph nodes. This upregulation of AID supports an AID-mediated mutational mechanism for the induction of $\mathrm{MM}$ and malignant lymphoma in these mice.

In humans, GBHs have been shown to increase the risk ratios for non-Hodgkins lymphomas (NHL) in several meta-analyses [2, 57-59]. For over 30 years, mouse models have been studied and evaluated as surrogates for NHL [60-64]. Classification systems for humans and mice indicate a strong similarity between malignant lymphomas in mice and NHL in humans.

Skin keratoacanthomas are increased by glyphosate in male SD rats and male Wistar rats. Skin basal-cell tumors are also increased in male SD rats in the reanalysis in this review. George et al. [35] exposed Swiss Albino mice to a glyphosate formulation (Roundup Original, $36 \mathrm{~g} / \mathrm{L}$ glyphosate) in a typical skin-painting initiationpromotion study using 12-o-tetradecanoylphorbol-13-acetate (TPA) as a promoter and 7,12-dimethyl-benz[a]anthracene (DMBA) as an initiator. The group exposed to DMBA followed by glyphosate demonstrated a significant increase $(p<0.05)$ in the number of animals with tumors $(40 \%$ of 
the treated animals versus no tumors in the controls) indicating the GBH has a promotional effect on carcinogenesis in the two-stage model in skin. Several in-vitro studies using human skin cells [65-67] have shown an increase in oxidative stress following exposure to glyphosate.

This review shows hepatocellular adenomas are increased by exposure to glyphosate in male SD rats and Wistar rats. Glyphosate has been shown to affect energy metabolism of mitochondria [68-71] and AST, ALT, and LDH [72] but not peroxisome proliferation or hypolipidemia [73] in the livers of Wistar rats. Transcriptome analyses of liver tissue in Sprague-Dwaley rats chronically exposed to the GBH Roundup Grand Travaux Plus suggest liver tissue damage is occurring [74]. Glyphosate and GBHs also seem to induce oxidative stress in the livers of several rat strains $[48,75,76]$.

Adrenal cortical carcinomas are increased in female Sprague-Dawley rats in the reanalysis in this review. There is also a suggestion of an increase in adrenal pheochromocytomas in male Wistar rats and of pituitary adenomas in male and female Wistar rats. Owagboriaye et al. [77] saw a significant increase in adrenal hormones aldostererone and corticosterone in a dose-dependent fashion following exposure to a GBH (Roundup Original) in male albino rats but not following exposure to equivalent doses of glyphosate (purity not given). Significant changes in adrenocorticotropic hormone were also seen for the GBH but not glyphosate. In contrast, Pandey and Rudraiah [78] saw a significant reduction in adrenocorticotropic hormone levels at similar doses in Wistar rats. Romano et al. (2010) saw a reduction in adrenal weights from exposure to the GBH Roundup Transorb in newly-weaned male Wistar rats but saw no differences in corticosterone levels except a rather large, non-statistical increase at the lowest exposure group. Changes in these and other hormones in these three papers suggest GBHs could have an impact on the hypothalamic-pituitaryadrenal axis that, after lifetime exposure, could induce cancers in the adrenal cortex and/or pituitary.

This reanalysis shows an inconsistent effect of glyphosate on the rates of mammary gland adenomas, carcinomas and combined adenomas and carcinomas in female Wistar rats but not in SD rats. Seralini et al. (2014) [36] saw an increase in mammary tumors in female SD rats exposed to the GBH GT Plus with associated hypertrophies and hyperplasia. Glyphosate and GBHs have also been shown to disrupt estrogen receptor alpha in rats [79] and to alter cellular replication and genotoxicity in estrogen-sensitive cell lines [80-86].

The longest study in male Sprague-Dawley rats showed an increase in testicular interstitial cell tumors after reanalysis. Several studies have seen changes in aromatase, testosterone and/or estrogen levels in male rats exposed to glyphosate or GBHs [84, 87-93].
The reanalysis in this review show an inconsistent increase in thyroid C-cell adenomas and/or carcinomas in male and female SD rats and thyroid follicular cell adenomas in male SD rats. De Souza et al. [94] exposed male Wistar rats to the GBH Roundup Transorb from gestational day 18 to postnatal day 5 and examined the animals for thyroid hormone effects at postnatal day 90. They saw dose-dependent decreases in thyroid stimulating hormone but no changes in circulating triiodothyronine or thyroxine. Genomic analysis suggested that genes involved in thyroid hormone metabolism and transport were probably involved in these alterations. In humans, Samsel et al. [95] hypothesized that glyphosate intake could interfere with selenium uptake, impacting thyroid hormone synthesis and increasing thyroid cancer risks. Using data from the Agricultural Health Study, Shrestha et al. [96] saw an association between ever/never use by farmworkers of GBHs and hypothyroidism $(\mathrm{OR}=1.28$, 95\% CI 1.071.52) and for the two lowest categories of intensity of use, but not the highest category.

\section{False positive errors}

The evaluation of any one animal cancer study involves a large number of statistical tests that could lead to false positives. To evaluate this issue, the probability that all of the results in any sex/species/strain could be due to false positive results is calculated. Overall, a total of 496 evaluations are done for these 13 studies including the few evaluations done against historical controls. There are 41 evaluations at 37 tumor/site combinations with a trend test $p \leq 0.05$; the probability that all of these are due to false positives is 0.001 . Similarly, looking at the evaluations resulting in $p \leq 0.01$, the probability that all of the findings are due to false positives is $<0.001$. The strongest evidence is for male CD-1 mice, the probability of seeing 11 positive findings at $p \leq 0.05$ and 8 at $p \leq$ 0.01 are both below 0.001. (see Additional file 2: Table S14).

\section{Comparison to regulator reviews}

In their final report on the carcinogenicity of glyphosate, the EPA concluded that "Based on the weight-of-evidence evaluations, the agency has concluded that none of the tumors evaluated in individual rat and mouse carcinogenicity studies are treatment-related due to lack of pairwise statistical significance, lack of a monotonic dose response, absence of preneoplastic or related nonneoplastic lesions, no evidence of tumor progression, and/ or historical control information (when available). Tumors seen in individual rat and mouse studies were also not reproduced in other studies, including those conducted in the same animal species and strain at similar or higher doses." EFSA concluded "No evidence of 
carcinogenicity was confirmed by the large majority of the experts (with the exception of one minority view) in either rats or mice due to a lack of statistical significance in pair-wise comparison tests, lack of consistency in multiple animal studies and slightly increased incidences only at dose levels at or above the limit dose/MTD, lack of pre-neoplastic lesions and/or being within historical control range. The statistical significance found in trend analysis (but not in pair-wise comparison) per se was balanced against the former considerations." Other regulatory agencies used similar wording to describe their findings. Each of the issues cited in these summaries are discussed below.

Both EPA and EFSA describe a lack of significant pairwise comparisons as one reason for discarding positive findings due to positive trend analyses. This is in direct conflict with their guidelines $[38,39]$ which make it clear that a positive finding in either pairwise comparisons or trend tests should be sufficient to rule out chance. The net effect of requiring both tests to be positive is an increase the probability of a false negative finding.

EPA notes that a lack of monotonic dose-response was a factor in their evaluation and, even though not mentioned in EFSA's final conclusions, was also used by EFSA to eliminate positive findings. This restriction suggests a serious lack of understanding of statistical variation in tumor responses and the way in which trend tests treat this variation, especially when the lowest doses are close to the control response and the increased tumor response is low. The net effect of requiring monotonic dose-response is a severe reduction in the ability to detect a positive trend and a large increase in the probability of a false negative finding.

Both agencies note that a lack of preneoplastic or related non-neoplastic lesions led to the exclusion of some tumors. For some of the tumors mentioned above, this is the case, but certainly not for all of them as noted in the analyses shown in Tables 3, 4 and 5. In addition, both agencies failed to evaluate support in the scientific literature for any of the tumors and relied entirely on the cancer bioassay results alone to draw any conclusions. In this evaluation, changes in preneoplastic and non-neoplastic conditions are analyzed for all tissues showing positive tumor findings and in all studies with the same sex/species/strain using an appropriate trend test and many tissue changes that could relate to these tumors are identified.

Both EPA and EFSA noted that historical controls are used in their evaluations. However, in both cases, the agencies only cite the range of the historical controls as a factor when determining if a given positive cancer finding is caused by glyphosate. As noted by the IARC [40] "It is generally not appropriate to discount a tumour response that is significantly increased compared with concurrent controls by arguing that it falls within the range of historical controls." In general, the concurrent control group is the most appropriate for any statistical analysis of the data [38-40], however, historical controls can play an important role in evaluating changes in rare tumors and cases where it appears the control response is unreasonably low and the treated groups appear to be unchanged from each other and in the central area of the historical control data. In this evaluation, a formal statistical test [41] is used to evaluate the cancer data when it is appropriate to use historical controls rather than inappropriately using only the historical control range. In addition, in every case where EPA and EFSA noted a significant tumor response was in the range of the historical control data, the reanalysis in this paper using Tarone's test demonstrates greater statistical significance in the trend and in no case invalidates a positive trend (not shown for all cases).

EPA cites no evidence of tumor progression as a reason to exclude some of the cancer findings. For some tumors, such as malignant lymphomas, tumor progression is not an issue. In cases where there is clearly tumor progression such as for mammary gland adenomas and adenocarcinomas in study $\mathrm{M}$, the agency did not consider this progression to be compelling. In addition, in cases where there is a clear increase in carcinomas and a slight decrease in adenomas, as might occur if the chemical impacts a later stage in the carcinogenic process or is a promoter, the agency did not consider this possibility. Similar comments apply to EFSA's evaluation.

EFSA notes that many studies had positive findings at or above the limit dose/MTD as a reason for excluding many study findings. There is clear guidance in the literature and regulatory guidelines on what constitutes exceedance of the MTD and how to exclude these data $[39,40,97]$. In no case did EFSA or EPA conclude that the highest dose used in any study they reviewed exceeded the MTD. The limit dose derives from the OECD guidelines for combined chronic toxicity/carcinogenicity studies [98] which states that "For the chronic toxicity phase of the study, a full study using three dose levels may not be considered necessary, if it can be anticipated that a test at one dose level, equivalent to at least $1000 \mathrm{mg} / \mathrm{kg}$ body weight/day, is unlikely to produce adverse effects." It is difficult to understand how a finding of carcinogenicity at a dose above $1000 \mathrm{mg} / \mathrm{kg} /$ day can be excluded based upon this guidance if that dose does not exceed the MTD.

Both EFSA and EPA found that there was inconsistency between studies of the tumor response and used this reasoning to exclude several tumors. Part of this relates to findings appearing in only one sex or strain but not others; this happens quite often, for example see [99] for animal carcinogenicity findings for 111 known 
human carcinogens. The other part of this relates to the magnitude of the response in a specific sex/species/ strain; neither agency used a formal statistical method to evaluate this consistency. It is naive to assume that the raw tumor counts from studies done in different laboratories at different times using different diets, different exposure lengths and different sub-strains of animals would yield perfect agreement in response. EPA's FIFRA Science Advisory Panel, in their review of EPA's draft risk assessment [100] recommended EPA do a pooled analysis to determine an overall effect as does the IARC [40]. The pooled analyses presented in this evaluation properly adjust for study differences and demonstrate consistency for many of the tumors showing significant evidence of carcinogenicity in one or more studies and suggestive increases in carcinogenicity in other studies using the same sex/species/strain.

Finally, both agencies missed many of the tumors identified in this evaluation due to a failure to analyze all of the data using a trend test like the C-A test. EPA states that in 4 of the 8 rat carcinogenicity studies no tumors were identified for evaluation. For one of these studies [30], the data are unavailable for review and the doses are far below the MTD. For the remaining three studies [19-21], there are 5 positive findings not identified by the EPA. In the remaining 4 studies $[17,18,22$, $23]$ where they saw some tumors increased, they failed to identify 6 tumors identified in this reanalysis. EPA states that in 2 of the 6 mouse carcinogenicity studies no tumors were identified for evaluation. As noted in the Materials and methods section, one of these studies [24] was determined to have falsified data by EPA [25] and should not have been included in their evaluation. For the second study [26], the data are unavailable and could not be evaluated in this review. In the remaining four studies discussed by EPA [11-14], they missed 5 tumors identified in this evaluation (two identified through historical controls). In addition, they excluded one study [16] due to the presence of a viral infection within the colony; EPA gives no documentation of this viral infection and there is no indication within the study report of a viral infection nor any indication that these animals were unhealthy. This study has one significant finding not discussed by EPA and three marginally significant findings similar to those seen in CD-1 mice. EPA also failed to evaluate one study [13] considered in this evaluation which had two positive tumor findings. Thus, EPA discussed only 7 of the 21 statistically significant tumor increases in rats and 5 of the 16 significant tumor increases in mice. Similar comments apply to the EFSA review and all of the other regulatory reviews. To be fair to the regulatory agencies, it should be noted that the original study reports from the laboratories that did these studies also failed to identify many of the significant trends discussed in this review because they relied predominantly on pairwise evaluations like Fisher's exact test and failed to do any trend analyses. This would suggest that the regulatory agencies are relying upon the results of the analyses presented in the study reports rather than conducting their own thorough reanalysis of the data using trend tests.

The mechanisms through which glyphosate causes these tumors in laboratory animals are as controversial as the cancer findings themselves. The IARC Working Group [2] concluded there was strong evidence that glyphosate induces genotoxicity and oxidative stress. All of the regulatory reviews have concluded glyphosate is not genotoxic and most have concluded it does not cause oxidative stress. A complete review of this literature is beyond the scope of this manuscript, but as noted above, genotoxicity and oxidative stress are plausible mechanisms for many of these cancers. Also, as noted in the earlier discussion of related findings from the peerreviewed literature, some of the cancers may be due to glyphosate altering hormonal balance in the adrenal, pituitary and thyroid glands.

\section{Strength-of evidence conclusions}

In summary, exposure of rats and mice to glyphosate in 13 separate carcinogenicity studies demonstrates that glyphosate causes a variety of tumors that differ by sex, species, strain and length of exposure. To summarize the strength-of-evidence for each tumor, four categories are used. Clear evidence (CE) is indicated when the data demonstrate a causal linkage between glyphosate and the tumor based upon the reanalysis in this review and the available peer-reviewed literature. Some evidence (SE) is indicated when the data demonstrate a linkage between glyphosate and the tumor based upon the reanalysis in this review and the available peer-reviewed literature but chance, although unlikely, cannot be ruled out. Equivocal evidence (EE) also indicates the data demonstrate a linkage between glyphosate and the tumor based upon the reanalysis in this review and the available peer-reviewed literature, but chance is as likely an explanation for the association as is glyphosate. No evidence (NE) indicates any linkage between glyphosate and the tumor based upon the reanalysis in this review is almost certainly due to chance. The factors used to put tumors into these categories include the analyses of the individual studies, the consistency of the data across studies (the pooled analyses), the analyses using historical control data, the analyses of the non-neoplastic lesions, the mechanistic evidence and the associated scientific literature. These categorizations are presented in Table 6.

There is clear evidence that glyphosate causes hemangiosarcomas, kidney tumors and malignant lymphomas in male CD-1 mice and hemangiomas and malignant 
Table 6 Summary of level of evidence ${ }^{a}$ for tumors observed to have a significant trend in 13 rodent carcinogenicity studies in male and female, mice and rats ${ }^{b}$

\begin{tabular}{|c|c|c|c|c|c|c|c|c|}
\hline \multirow[t]{2}{*}{ Tumor } & \multicolumn{4}{|l|}{ Males } & \multicolumn{4}{|l|}{ Females } \\
\hline & CD-1 Mouse & Swiss Mouse & SD Rat & Wistar Rat & CD-1 Mouse & Swiss albino mouse & SD Rat & Wistar Rat \\
\hline Adrenal cortical carcinoma & & & & & & & CE & \\
\hline Adrenal pheochromocytoma & & & & & & & & $\mathrm{EE}$ \\
\hline Alviolar-Bronchiolar tumor & $\mathrm{NE}$ & & & & $\mathrm{NE}$ & & & \\
\hline Harderian gland tumor & & & & & NE & & & \\
\hline Hemangioma & & & & & CE & CE & & \\
\hline Hemangiosarcomas & CE & & & & & & & \\
\hline Kidney tumor & CE & SE & CE & & & & & \\
\hline Liver adenoma & & & CE & CE & & & & \\
\hline Mammary tumor & & & & & & & & SE \\
\hline Malignant lymphoma & CE & SE & & & CE & SE & & \\
\hline Pancreas Islet Cell tumor & & & $\mathrm{EE}$ & & & & & \\
\hline Pituitary adenomas & & & & SE & & & & SE \\
\hline Skin basal-cell tumor & & & $C E$ & & & & & \\
\hline Skin keratoacanthoma & & & $\mathrm{CE}$ & CE & & & & \\
\hline Thyroid C-cell tumor & & & $\mathrm{EE}$ & & & & EE & \\
\hline Thyroid follicular-cell tumor & & & $\mathrm{EE}$ & & & & & \\
\hline Testis interstitial-cell Tumor & & & SE & & & & & \\
\hline
\end{tabular}

lymphomas in female CD-1 mice. There is clear evidence that glyphosate causes hemangiomas in female Swiss albino mice. There is clear evidence that glyphosate causes kidney adenomas, liver adenomas, skin keratoacanthomas and skin basal cell tumors in male Sprague-Dawley rats and adrenal cortical carcinomas in female Sprague-Dawley rats. There is clear evidence that glyphosate causes hepatocellular adenomas and skin keratocanthomas in male Wistar rats.

There is some evidence that glyphosate causes malignant lymphomas in male and female and kidney tumors in male Swiss albino mice. There is some evidence that glyphosate causes testicular interstitial cell tumors in male Sprague-Dawley rats. There is some evidence that glyphosate causes pituitary adenomas in male and female Wistar rats and mammary gland adenomas and carcinomas in female Wistar rats.

There is equivocal evidence that glyphosate causes thyroid c-cell adenomas and carcinomas in male and female Sprague-Dawley rats, and thyroid follicular cell adenomas and carcinomas and pancreas islet-cell adenomas in male Sprague-Dawley rats. There is equivocal evidence glyphosate causes adrenal pheochromocytomas in male Wistar rats.

There is no evidence that glyphosate causes lung tumors in male and female CD-1 mice or Harderian gland tumors in female CD-1 mice.
The analyses conducted for this review clearly support the IARC's conclusion that there is sufficient evidence to say that glyphosate causes cancer in experimental animals. In contrast, the regulatory authorities reviewing these data appear to have relied on analyses conducted by the registrant and not their own analyses of the data. As such, they uniformly concluded that the subset of tumor increases they identified as showing an association with glyphosate were due to chance. Had regulatory authorities conducted a full reanalysis of all of the available evidence from the 13 animal carcinogenicity studies as was done here, it is difficult to see how they could reach any conclusion other than glyphosate can cause cancers in experimental animals.

\section{Reviewer's report}

\section{Level of interest}

Please indicate how interesting you found the manuscript:

An exceptional article

\section{Quality of written English}

Please indicate the quality of language in the manuscript: Acceptable

\section{Declaration of competing interests}

Please complete a declaration of competing interests, considering the following questions: 
1. Have you in the past five years received reimbursements, fees, funding, or salary from an organisation that may in any way gain or lose financially from the publication of this manuscript, either now or in the future?

2. Do you hold any stocks or shares in an organisation that may in any way gain or lose financially from the publication of this manuscript, either now or in the future?

3. Do you hold or are you currently applying for any patents relating to the content of the manuscript?

4. Have you received reimbursements, fees, funding, or salary from an organization that holds or has applied for patents relating to the content of the manuscript?

5. Do you have any other financial competing interests?

6. Do you have any non-financial competing interests in relation to this paper?

If you can answer no to all of the above, write 'I declare that I have no competing interests' below.

If your reply is yes to any, please give details below.

I declare that I have no competing interests

I agree to the open peer review policy of the journal. I understand that my name will be included on my report to the authors and, if the manuscript is accepted for publication, my named report including any attachments I upload will be posted on the website along with the authors' responses. I agree for my report to be made available under an Open Access Creative Commons CC-BY license (http://creativecommons.org/licenses/by/4.0/). I understand that any comments which I do not wish to be included in my named report can be included as confidential comments to the editors, which will not be published.

I agree to the open peer review policy of the journal

\section{Supplementary information}

Supplementary information accompanies this paper at https://doi.org/10. 1186/s12940-020-00574-1.

Additional file 1. Details on individual animal chronic exposure toxicity and carcinogenicity studies.

Additional file 2: Table S1. Tumors of interest in male and female CD1 mice from the 24-month feeding study of Knezevich and Hogan (1983) [11] - Study A. Table S2. Tumors of interest in male and female CD-1 mice from the 24-month feeding study of Atkinson et al. (1993) [12] Study B. Table S3. Tumors of interest in male and female CD-1 mice from the 18-month feeding study of Sugimoto (1997) [13] - Study C. Table S4. Tumors of interest in male and female CD-1 mice from the 18 month feeding study of Wood et al. (2009) [14] - Study D. Table S5. Tumors of interest in male and female CD-1 mice from the 18-month feeding study of Takahashi (1999) [15]; data extracted from JMPR [7] - Study E. Table S6. Tumors of interest in male and female Swiss Albino mice from the 18-month feeding study of Kumar (2001) [16] - Study F. Table S7. Tumors of interest in male and female Sprague-Dawley rats the 26- month feeding study of Lankas (1981) [17] - Study G. Table S8. Tumors of interest in male and female Sprague-Dawley rats from the 24-month feeding study of Stout and Ruecker (1990) [18] - Study H. Table S9. Tumors of interest in male and female Sprague-Dawley rats from the 24month feeding study of Atkinson et al. (1993) [19] - Study I. Table S10. Tumors of interest in male and female Sprague-Dawley rats from the 24month feeding study of Enemoto (1997) [20] - Study J. Table S11. Tumors of interest in male and female Wistar rats from the 24-month feeding study of Suresh (1996) [21] - Study K. Table S12. Tumors of interest in male and female Wistar rats from the 24-month feeding study of Brammer (2001) [22] - Study L. Table S13. Tumors of interest in male and female Wistar rats from the 24-month feeding study of Wood et al. (2009) [23] - Study M. Table S14. Observed (Obs.) versus expected (Exp.) tumor sites with significant trends in the 13 acceptable rodent carcinogenicity studies using glyphosate.

\section{Abbreviations}

AID: Activation-induced cytidine deaminase; ALT: Alanine aminotransferase; AST: Aspartate aminotransferase; DMBA: 7,12-dimethyl-benz[a]anthracene; EChA: European Chemicals Agency; EFSA: European Food Safety Authority; EPA: US Environmental Protection Agency; GBH: Glyphosate-based herbicide; GSH: Glutathione; IARC: International Agency for Research on Cancer; JMPR: Joint Meeting of the FAO Panel of Experts on Pesticide Residues in Food and the Environment and the WHO Core Assessment Group on Pesticide Residues; LDH: Lactic acid dehydrogenase; MDA: Malondialdehyde; $\mathrm{mg} / \mathrm{kg} / \mathrm{d}$ : Milligrams per kilogram body weight per day; MM: Multiple myeloma; MTD: Maximum tolerated dose; OECD: Organization for Economic Cooperation and Development; SD rat: Sprague-Dawley rat; TPA: 12-otetradecanoylphorbol-13-acetate; WT: Wild type

\section{Acknowledgements}

Not applicable.

\section{Authors' contributions}

All work on this manuscript was done by CJP. No other persons have contributed to or reviewed this manuscript prior to submission. The author read and approved the final manuscript.

\section{Funding}

Some of the analyses were conducted to develop expert opinions for court cases and were supported by funding from attorneys involved in these litigations. Some of the text and tables in this manuscript are duplicative of written expert testimony by CJP for these court cases. These funders had no role in the design of the study and collection, analysis, and interpretation of data and in writing the manuscript.

\section{Availability of data and materials}

The original reports for 12 of the animal carcinogenicity studies that support the findings of this study are available from EFSA, but restrictions apply to the availability of these data. All tumor data cited in this study are included in this published article [and its supplementary information files]. Additional data (historical control data, non-significant cancer sites, non-neoplastic endpoints, etc.) are available from the author upon reasonable request.

Ethics approval and consent to participate

All animal carcinogenicity studies used in this evaluation underwent ethics approval by the original study laboratory.

\section{Consent for publication}

Not applicable

\section{Competing interests}

CJP has been paid to provide expert testimony for litigation on the carcinogenicity of glyphosate.

\section{Author details}

${ }^{1}$ Rollins School of Public Health, Emory University, Atlanta, GA, USA. ${ }^{2}$ Department of Toxicogenomics, Maastricht University, Maastricht, Netherlands. ${ }^{3} \mathrm{CJP}$ Consulting, Seattle, Washington, USA. 


\section{Received: 10 December 2019 Accepted: 6 February 2020}

\section{Published online: 12 February 2020}

\section{References}

1. Székács A, Darvis B. Forty years with glyphosate. In: Hasaneen M-G, editor. Herbicides - properties, synthesis and control of weeds. Croatia: InTech; 2012. p. 38

2. IARC Working Group. Glyphosate. In: Some Organophosphate Insecticides and Herbicides: Diazinon, Glyphosate, Malathion, Parathion, and Tetrachlorvinphos, vol. 112. Lyon: IARC Monogr Prog; 2015. p. 1-92.

3. Benbrook CM. Trends in glyphosate herbicide use in the United States and globally. Environ Sci Eur. 2016;28(1):3.

4. European Food Safety Authority. Conclusion on the peer review of the pesticide risk assessment of the active substance glyphosate. EFSA J. 2015:13(11):4302.

5. Committee for Risk Assessment. Opinion proposing harmonised classification and labelling at EU level of glyphosate (ISO); N(phosphonomethyl)glycine. Helsinki: European Chemical Agency; 2017.

6. EPA. Revised Glyphosate Issue Paper: Evaluation of Carcinogenic Potential. Washington: US Environmental Protection Agency; 2017.

7. JMPR. Report of the special session of the joint Meeting of the FAO Panel of experts on pesticide residues in food and the environment and the WHO Core assessment group on pesticide residues Geneva, Switzerland, 9-13 may 2016, vol. 227. Geneva: Food and Agriculture Agency and World Health Organization; 2017.

8. BFR. In: Assessment GFIfR, editor. Final Addendum to the Renewal Assessment Report: Glyphosate. Parma: European Food Safety Authority; 2015.

9. Greim H, Saltmiras D, Mostert V, Strupp C. Evaluation of carcinogenic potential of the herbicide glyphosate, drawing on tumor incidence data from fourteen chronic/carcinogenicity rodent studies. Crit Rev Toxicol. 2015;45(3):185-208

10. European Court of Justice. Judgment of the General Court of 7 March 2019 -Hautala and Others v EFSA. Luxembourg: European Court of Justice; 2019.

11. Knezevich AL, Hogan GK. A chronic feeding study of glyphosate in mice: Monsanto. East Millstone: Bio/Dynamic Inc.; 1983. Report No. 77-2011. ; 1983.

12. Atkinson C, Martin T, Hudson P, Robb D. Glyphosate: 104 week dietary carcinogenicity study in mice. In: Inveresk Research International. Tranent: IRI Project No. 438618; 1993

13. Sugimoto K. 18-Month Oral Oncogenicity Study in Mice, Vol. 1 and 2. Kodaira-shi: The Institute of Environmental Toxicology; 1997. Study No.IET 94-0151.

14. Wood E, Dunster J, Watson P, Brooks P. Glyphosate Technical: Dietary Carcinogenicity Study in the Mouse. Derbyshire: Harlan Laboratories Limited; 2009. Study No. 2060-011.

15. Takahashi M. Oral feeding carcinogenicity study in mice with AK-01. Agatsuma: Nippon Experimental Medical Research Institute Co. Ltd.; 1999.

16. Kumar DPS. Carcinogenicity Study with Glyphosate Technical in Swiss Albino Mice. In: Toxicology Department Rallis Research Centre, Rallis India Limited; 2001. Study No. TOXI: 1559.CARCI-M.

17. Lankas GP. A Lifetime Study of Glyphosate in Rats. Monsanto: Report No. 77-2062 prepared by Bio Dynamics, Inc.; 1981.

18. Stout LD, Ruecker PA. Chronic study of glyphosate administered in feed to albino rats. Monsanto: Monsanto Chemical Company; 1990.

19. Atkinson C, Strutt A, Henderson W, et al: 104-Week Chronic Feeding/ Oncogenicity study in rats with 52-week interim kill. 1993.

20. Enemoto K. 24-Month Oral Chronic Toxicity and Oncogenicity Study in Rats, Vol. 1. Kodaira-shi: The Institute of Environmental Toxicology; 1997.

21. Suresh TP. Combined chronic toxicity and carcinogenicity study with glyphosate technical in Wistar rats. Syngenta: Toxicology Department Rallis Research Centre, Rallis India Limited; 1996.

22. Brammer. Glyphosate Acid: Two Year Dietary Toxicity and Oncogenicity Study in Wistar Rats. Cheshire: Central Toxicology Laboratory, Alderley Park Macclesfield; 2001

23. Wood E, Dunster J, Watson P, Brooks P. Glyphosate Technical: Dietary Combined Chronic Toxicity/Carcinogenicity Study in the Rat. Derbyshire: Harlan Laboratories Limited; 2009. Study No. 2060-012.

24. Reyna MS, Gordon DE. 18-month carcinogenicity study with CP67573 in Swiss white mice: Monsanto. Northbrook: Industrial Bio-Test Laboratories, Inc.; 1973

25. USEPA. In: O'ffice of Pesticides Program, editor. Summary of the IBT Review Program, vol. 46. Washington: US Environmental Protection Agency; 1983.
26. Pavkov K, Turnier JC. Two-year chronic toxicity and Oncogenecity dietary study with SC-0224 in mice. Farmington: Stauffer Chemical Company; 1987.

27. Reyna MS, Gordon DE. Two- Year Chronic Oral Toxicity Study with CP67573 in Albino Rats: Monsanto; 1974.

28. Burnett P, Borders J, Kush J. In: on behalf of Monsanto Co., editor. Report to Monsanto Company: Two Year Chronic Oral Toxicity Study with CP- 76100 in Albino Rats. Northbrook: Industrial Bio-Test Laboratories, Inc; 1979.

29. EPA. Glyphosate Issue Paper: Evaluation of Carcinogenic Potential. Washington: US Environmental Protection Agency; 2016.

30. Pavkov K, Wyand S. Two-year chronic toxicity and Oncogenecity dietary study with SC-0224 in rats. Farmington: Stauffer Chemical Company; 1987.

31. USEPA. Data evaluation report (accession number 4021 40-06). In. Edited by branch T. Washington: USEPA; 1987.

32. Excel. Combined chronic toxicity/carcinogenicity study of glyphosate technical in Sprague Dawley rats. Pune: Indian Institute of Toxicology; 1997.

33. Takahashi M. A combined chronic toxicity/carcinogenicity study of AK-01 bulk substance by dietary administration in rats. Agatsuma: Nippon Experimental Medical Research Institute Co. Ltd.; 1999.

34. Chruscielska K, Brzezinski J, Kita K, Kalhorn D, Kita I, Graffstein B, Korzeniowski P. Glyphosate: evaluation of chronic activity and possible far reaching effects - part 1. Studies on chronic toxicity. Pestycydy. 2000;3-4:10.

35. George J, Prasad S, Mahmood Z, Shukla Y. Studies on glyphosate-induced carcinogenicity in mouse skin: a proteomic approach. J Proteome. 2010; 73(5):951-64.

36. Seralini GE, Clair E, Mesnage R, Gress S, Defarge NS, Malatesta M, Hennequin $\mathrm{D}$, de Vendomois J. Republished study: long-term toxicity of a roundup herbicide and a roundup-tolerant genetically modified maize. Environ Sci Eur. 2014;26(1):14

37. Gart JJ, Chu KC, Tarone RE. Statistical issues in interpretation of chronic bioassay tests for carcinogenicity. J Natl Cancer Inst. 1979;62(4):957-74.

38. OECD. In: environment HaSP, editor. Guidance document 116 on the conduct and Design of Chronic Toxicity and Carcinogenicity Studies. Paris: OECD; 2012

39. USEPA: Guidelines for Carcinogen Risk Assessment. In. Edited by Agency UEP. Washington: US Environmental Protection Agency; 2005: 166.

40. Preamble to the IARC Monographs [https://monographs.iarc.fr/wp-content/ uploads/2019/01/Preamble-2019.pdf].

41. Tarone RE. The use of historical control information in testing for a trend in proportions. Biometrics. 1982:38(1):215-20.

42. Dykstra W. In: branch T, editor. Glyphosate - EPA registration Nos. 524-318 and 524-333 - historical control data for mouse kidney tumors. Washington, DC: US EPA; 1989.

43. Giknis M, Clifford C. Spontaneous neoplastic lesions in the Crl:CD-1(ICR)BR mouse. Wilmington: Charles River Laboratories; 2000.

44. EPA. EPA Memo Stout and Ruecker. In: Dykstra W, editor. Toxicology Branch l; 1991. MRID 416438-01 Tox review 008897.

45. Isobe K, Mukaratirwa S, Petterino C, Bradley A. Historical control background incidence of spontaneous thyroid and parathyroid glands lesions of rats and CD-1 mice used in 104-week carcinogenicity studies. J Toxicol Pathol. 2016:29(3):201-6.

46. Turkmen R, Birdane YO, Demirel HH, Yavuz H, Kabu M, Ince S. Antioxidant and cytoprotective effects of $\mathrm{N}$-acetylcysteine against subchronic oral glyphosate-based herbicide-induced oxidative stress in rats. Environ Sci Pollut Res Int. 2019:26(11):11427-37.

47. Dedeke GA, Owagboriaye FO, Ademolu KO, Olujimi OO, Aladesida AA. Comparative assessment on mechanism underlying renal toxicity of commercial formulation of roundup herbicide and glyphosate alone in male albino rat. Int J Toxicol. 2018:37(4):285-95.

48. Tang J, Hu P, Li Y, Win-Shwe T, Li C. lon imbalance is involved in the mechanisms of liver oxidative damage in rats exposed to glyphosate. Front Physiol. 2017;8:1083.

49. Hamdaoui L, Naifar M, Mzid M, Ben Salem M, Chtourou A, Makni-Ayadi F, Sahnoun Z, Rebai T. Nephrotoxicity of Kalach 360 SL: biochemical and histopathological findings. Toxicol Mech Methods. 2016;26(9):685-91.

50. Tizhe EV, Ibrahim ND, Fatihu MY, Onyebuchi II, George BD, Ambali SF, Shallangwa JM. Influence of zinc supplementation on histopathological changes in the stomach, liver, kidney, brain, pancreas and spleen during subchronic exposure of Wistar rats to glyphosate. Comp Clin Pathol. 2014; 23(5):1535-43.

51. Cavusoglu K, Yapar K, Oruc E, Yalcin E. Protective effect of Ginkgo biloba L. leaf extract against glyphosate toxicity in Swiss albino mice. J Med Food. 2011;14(10):1263-72 
52. Wang L, Deng Q, Hu H, Liu M, Gong Z, Zhang S, Xu-Monette ZY, Lu Z, Young $\mathrm{KH}, \mathrm{Ma} \mathrm{X}$, et al. Glyphosate induces benign monoclonal gammopathy and promotes multiple myeloma progression in mice. J Hematol Oncol. 2019;12(1):70.

53. Gunatilake S, Seneff S, Orlando L. Glyphosate's Synergistic Toxicity in Combination with Other Factors as a Cause of Chronic Kidney Disease of Unknown Origin. Int J Environ Res Public Health. 2019;16(15):2734.

54. Jayasumana C, Gunatilake S, Siribaddana S. Simultaneous exposure to multiple heavy metals and glyphosate may contribute to Sri Lankan agricultural nephropathy. BMC Nephrol. 2015;16:103.

55. Jayasumana C, Paranagama P, Agampodi S, Wijewardane C, Gunatilake S, Siribaddana S. Drinking well water and occupational exposure to herbicides is associated with chronic kidney disease, in Padavi-Sripura, Sri Lanka. Environ Health. 2015;14:6.

56. Zhang F, Pan LP, Ding EM, Ge QJ, Zhang ZH, Xu JN, Zhang L, Zhu BL. Study of the effect of occupational exposure to glyphosate on hepatorenal function. Zhonghua Yu Fang Yi Xue Za Zhi. 2017;51(7):615-20.

57. Zhang L, Rana I, Shaffer RM, Taioli E, Sheppard L. Exposure to glyphosatebased herbicides and risk for non-Hodgkin lymphoma: a meta-analysis and supporting evidence. Mutat Res. 2019;781:186-206.

58. Chang ET, Delzell E. Systematic review and meta-analysis of glyphosate exposure and risk of lymphohematopoietic cancers. J Environ Sci Health B. 2016;51:1-27.

59. Schinasi L, Leon ME. Non-Hodgkin lymphoma and occupational exposure to agricultural pesticide chemical groups and active ingredients: a systematic review and meta-analysis. Int J Environ Res Public Health. 2014; 11(4):4449-527.

60. Begley DA, Sundberg JP, Krupke DM, Neuhauser SB, Bult CJ, Eppig JT, Morse $\mathrm{HC}$ 3rd, Ward JM. Finding mouse models of human lymphomas and leukemia's using the Jackson laboratory mouse tumor biology database. Exp Mol Pathol. 2015;99(3):533-6.

61. Hori M, Xiang S, Qi CF, Chattopadhyay SK, Fredrickson TN, Hartley JW, Kovalchuk AL, Bornkamm GW, Janz S, Copeland NG, et al. Non-Hodgkin lymphomas of mice. Blood Cells Mol Dis. 2001;27(1):217-22.

62. Morse HC 3rd, Ward JM, Teitell MA. Mouse models of human B lymphoid neoplasms. In: Magrath IT, editor. The Lymphoid Neoplasms. 3rd ed. Boca Ratan: CRC Press; 2010

63. Pattengale PK, Taylor CR. Experimental models of lymphoproliferative disease. The mouse as a model for human non-Hodgkin's lymphomas and related leukemias. Am J Pathol. 1983;113(2):237-65.

64. Ward JM. Lymphomas and leukemias in mice. Exp Toxicol Pathol. 2006; 57(5-6):377-81.

65. Elie-Caille C, Heu C, Guyon C, Nicod L. Morphological damages of a glyphosate-treated human keratinocyte cell line revealed by a microto nanoscale microscopic investigation. Cell Biol Toxicol. 2010;26(4): $331-9$.

66. Heu C, Berquand A, Elie-Caille C, Nicod L. Glyphosate-induced stiffening of HaCaT keratinocytes, a peak force tapping study on living cells. J Struct Biol. 2012:178(1):1-7.

67. Heu C, Elie-Caille C, Mougey V, Launay S, Nicod L. A step further toward glyphosate-induced epidermal cell death: involvement of mitochondrial and oxidative mechanisms. Environ Toxicol Pharmacol. 2012;34(2):144-53

68. Olorunsogo OO, Bababunmi EA, Bassir O. Effect of glyphosate on rat liver mitochondria in vivo. Bull Environ Contam Toxicol. 1979;22(3):357-64.

69. Olorunsogo $\mathrm{OO}$, Bababunmi EA. Inhibition of succinate-linking reduction of pyridine nucleotide in rat liver mitochondria 'in vivo' by $\mathrm{N}$ (phosphonomethyl)glycine. Toxicol Lett. 1980;7(2):149-52.

70. Olorunsogo $\mathrm{OO}$. Defective nicotinamide nucleotide transhydrogenase reaction in hepatic mitochondria of $\mathrm{N}$-(phosphonomethyl)-glycine treated rats. Biochem Pharmacol. 1982;31(12):2191-2.

71. Olorunsogo OO. Inhibition of energy-dependent transhydrogenase reaction by $\mathrm{N}$-(phosphonomethyl) glycine in isolated rat liver mitochondria. Toxicol Lett. 1982;10(1):91-5.

72. Haskovic E, Pekic M, Focak M, Sulejevic D, Mesalic L. Effects of glyphosate on enzyme activity and serum glucose in rats Rattus norvegicus. Acta VetBeogr. 2016;66(2):214-21.

73. Vainio H, Linnainmaa K, Kahonen M, Nickels J, Hietanen E, Marniemi J, Peltonen P. Hypolipidemia and peroxisome proliferation induced by phenoxyacetic acid herbicides in rats. Biochem Pharmacol. 1983;32(18): 2775-9.
74. Mesnage R, Arno M, Costanzo M, Malatesta M, Seralini GE, Antoniou MN Transcriptome profile analysis reflects rat liver and kidney damage following chronic ultra-low dose roundup exposure. Environ Health. 2015;14:70.

75. Turkmen R, Birdane YO, Demirel HH, Kabu M, Ince S. Protective effects of resveratrol on biomarkers of oxidative stress, biochemical and histopathological changes induced by sub-chronic oral glyphosate-based herbicide in rats. Toxicol Res (Camb). 2019;8(2):238-45.

76. Astiz M, de Alaniz MJ, Marra CA. The oxidative damage and inflammation caused by pesticides are reverted by lipoic acid in rat brain. Neurochem Int. 2012;61(7):1231-41.

77. Owagboriaye F, Dedeke G, Ademolu K, Olujimi O, Aladesida A, Adeleke M. Comparative studies on endogenic stress hormones, antioxidant, biochemical and hematological status of metabolic disturbance in albino rat exposed to roundup herbicide and its active ingredient glyphosate. Environ Sci Pollut Res Int. 2019;26(14):14502-12.

78. Pandey A, Rudraiah M. Analysis of endocrine disruption effect of roundup((R)) in adrenal gland of male rats. Toxicol Rep. 2015;2:1075-85.

79. Lorenz V, Milesi MM, Schimpf MG, Luque EH, Varayoud J. Epigenetic disruption of estrogen receptor alpha is induced by a glyphosate-based herbicide in the preimplantation uterus of rats. Mol Cell Endocrinol. 2019; 480:133-41.

80. LKS DA, Pletschke BI, Frost CL. Moderate levels of glyphosate and its formulations vary in their cytotoxicity and genotoxicity in a whole blood model and in human cell lines with different estrogen receptor status. 3 Biotech. 2018;8(10):438.

81. Gasnier C, Dumont C, Benachour N, Clair E, Chagnon MC, Seralini GE. Glyphosate-based herbicides are toxic and endocrine disruptors in human cell lines. Toxicology. 2009;262(3):184-91.

82. Hokanson R, Fudge R, Chowdhary R, Busbee D. Alteration of estrogenregulated gene expression in human cells induced by the agricultural and horticultural herbicide glyphosate. Hum Exp Toxicol. 2007;26(9):747-52.

83. Mesnage R, Phedonos A, Biserni M, Arno M, Balu S, Corton JC, Ugarte R, Antoniou MN. Evaluation of estrogen receptor alpha activation by glyphosate-based herbicide constituents. Food Chem Toxicol. 2017;108(Pt A):30-42.

84. Nardi J, Moras PB, Koeppe C, Dallegrave E, Leal MB, Rossato-Grando LG. Prepubertal subchronic exposure to soy milk and glyphosate leads to endocrine disruption. Food Chem Toxicol. 2017:100:247-52.

85. Sritana N, Suriyo T, Kanitwithayanun J, Songvasin BH, Thiantanawat A, Satayavivad J. Glyphosate induces growth of estrogen receptor alpha positive cholangiocarcinoma cells via non-genomic estrogen receptor/ERK1/ 2 signaling pathway. Food Chem Toxicol. 2018;118:595-607.

86. Thongprakaisang S, Thiantanawat A, Rangkadilok N, Suriyo T, Satayavivad J. Glyphosate induces human breast cancer cells growth via estrogen receptors. Food Chem Toxicol. 2013;59:129-36.

87. Cassault-Meyer E, Gress S, Seralini GE, Galeraud-Denis I. An acute exposure to glyphosate-based herbicide alters aromatase levels in testis and sperm nuclear quality. Environ Toxicol Pharmacol. 2014;38(1):131-40.

88. Clair E, Mesnage R, Travert C, Seralini GE. A glyphosate-based herbicide induces necrosis and apoptosis in mature rat testicular cells in vitro, and testosterone decrease at lower levels. Toxicol in Vitro. 2012;26(2):269-79.

89. Astiz M. Hurtado de Catalfo GE, Garcia MN, Galletti SM, Errecalde AL, de Alaniz MJ, Marra CA: pesticide-induced decrease in rat testicular steroidogenesis is differentially prevented by lipoate and tocopherol. Ecotoxicol Environ Saf. 2013:91:129-38.

90. Dallegrave E, Mantese FD, Oliveira RT, Andrade AJ, Dalsenter PR, Langeloh A. Pre- and postnatal toxicity of the commercial glyphosate formulation in Wistar rats. Arch Toxicol. 2007;81(9):665-73.

91. Owagboriaye FO, Dedeke GA, Ademolu KO, Olujimi OO, Ashidi JS, Adeyinka AA. Reproductive toxicity of roundup herbicide exposure in male albino rat. Exp Toxicol Pathol. 2017;69(7):461-8.

92. Romano MA, Romano RM, Santos LD, Wisniewski P, Campos DA, de Souza PB, Viau P, Bernardi MM, Nunes MT, de Oliveira CA. Glyphosate impairs male offspring reproductive development by disrupting gonadotropin expression. Arch Toxicol. 2012;86(4):663-73.

93. Romano RM, Romano MA, Bernardi MM, Furtado PV, Oliveira CA. Prepubertal exposure to commercial formulation of the herbicide glyphosate alters testosterone levels and testicular morphology. Arch Toxicol. 2010;84(4):309-17.

94. de Souza JS, Kizys MM, da Conceicao RR, Glebocki G, Romano RM, OrtigaCarvalho TM, Giannocco G, da Silva ID, Dias da Silva MR, Romano MA, et al. 
Perinatal exposure to glyphosate-based herbicide alters the thyrotrophic axis and causes thyroid hormone homeostasis imbalance in male rats. Toxicology. 2017;377:25-37.

95. Samsel A, Seneff S. Glyphosate, pathways to modern diseases II: celiac sprue and gluten intolerance. Interdiscip Toxicol. 2013;6(4):159-84.

96. Shrestha S, Parks CG, Goldner WS, Kamel F, Umbach DM, Ward MH, Lerro CC, Koutros S, Hofmann JN, Beane Freeman LE, et al. Pesticide use and incident hypothyroidism in pesticide applicators in the agricultural health study. Environ Health Perspect. 2018;126(9):97008.

97. OECD: Carcinogenicity Studies, OECD Guideline for the Testing of Chemicals, No. 451. In. Edited by OECD. Paris: Organization for Economic Co-operation and Development; 2009

98. OECD: Combined Chronic Toxicity \Carcinogenicity Studies, OECD Guidelines for Testing of Chemicals, No. 453. In. Edited by OECD. Paris: Organization for Economic Co-operation and Development; 2009.

99. Krewski D, Rice JM, Bird M, Milton B, Collins B, Lajoie P, Billard M, Grosse Y, Cogliano VJ, Caldwell JC, et al. Concordance between sites of tumor development in humans and in experimental animals for 111 agents that are carcinogenic to humans. J Toxicol Environ Health B Crit Rev. 2019;22(78):203-36.

100. FIFRA Scientific Advisory Panel Meeting Minutes. In: Programs OoP, editor. Meeting Minutes and Final Report of the December 13-16, 2016 FIFRA SAP Meeting Held to Consider and Review Scientific Issues Associated with EPA's Evaluation of the Carcinogenic Potential of Glyphasate, vol. 101. Washington, DC: US Environmental Protection Agency; 2017.

\section{Publisher's Note}

Springer Nature remains neutral with regard to jurisdictional claims in published maps and institutional affiliations.

Ready to submit your research? Choose BMC and benefit from:

- fast, convenient online submission

- thorough peer review by experienced researchers in your field

- rapid publication on acceptance

- support for research data, including large and complex data types

- gold Open Access which fosters wider collaboration and increased citations

- maximum visibility for your research: over $100 \mathrm{M}$ website views per year

At $\mathrm{BMC}$, research is always in progress.

Learn more biomedcentral.com/submissions 